\title{
Synergistic associations of physical activity and diet quality on cardiometabolic risk factors in overweight and obese postmenopausal women
}

\author{
Marie-Eve Lavoie ${ }^{1,2}$, May Faraj ${ }^{1,2,3}$, Irene Strychar ${ }^{1,3,4}$, Éric Doucet ${ }^{5}$, Martin Brochu ${ }^{6,7}$, \\ Jean-Marc Lavoie ${ }^{8}$ and Rémi Rabasa-Lhoret ${ }^{1,2,3 *}$ \\ ${ }^{1}$ Département de Nutrition, Faculté de Médecine, Université de Montréal, Montreal, QC, Canada H3T 1A8 \\ ${ }^{2}$ Institut de Recherches Cliniques de Montréal (IRCM), 110 Avenue des Pins Ouest, Montreal, QC, Canada H2W 1R7 \\ ${ }^{3}$ Montreal Diabetes Research Center (MDRC), Montreal, QC, Canada \\ ${ }^{4}$ Centre de Recherche du Centre Hospitalier de l'Université de Montréal (CRCHUM), Montreal, QC, Canada \\ ${ }^{5}$ Behavioural and Metabolic Research Unit, Faculty of Health Sciences, School of Human Kinetics, University of Ottawa, \\ Ottawa, ON, Canada \\ ${ }^{6}$ Faculté d'éducation Physique et Sportive, Université de Sherbrooke, Sherbrooke, QC, Canada \\ ${ }^{7}$ Centre de Santé et de Services Sociaux, Institut Universitaire de Gériatrie de Sherbrooke, Sherbrooke, QC, Canada \\ ${ }^{8}$ Département de Kinésiologie, Université de Montréal, QC, Canada
}

(Submitted 9 July 2011 - Final revision received 12 March 2012 - Accepted 12 March 2012 - First published online 9 May 2012)

\section{Abstract}

Healthy diet and physical activity are associated with a lower cardiometabolic risk (CMR). Little is known about whether they interact to improve CMR. The purpose of the present study was to determine the synergistic associations of diet quality and physical activity energy expenditure (PAEE) on CMR factors. The present study was an a posteriori analysis of two cross-sectional studies on 124 inactive nondiabetic postmenopausal women with a BMI $\geq 27 \mathrm{~kg} / \mathrm{m}^{2}$. The following factors were measured: diet quality (assessed by the Canadian Healthy Eating Index (C-HEI) from a $3 \mathrm{~d}$ food record); PAEE (doubly labelled water); body composition (dual-energy X-ray absorptiometry, computed tomography scan); lipoprotein profile (total, HDL- and LDL-cholesterol (HDL-C and LDL-C), non-HDL-C, total cholesterol:HDL-C, TAG, apoA1, apoB, apoA1:apoB and LDL-C:apoB); insulin sensitivity (homeostasis model assessment of insulin resistance and hyperinsulinaemic-euglycaemic clamp); inflammatory markers (high-sensitivity C-reactive protein (hs-CRP), haptoglobin, orosomucoid, IL-6 and leucocyte count). The association of the interaction PAEE $\times$ C-HEI and CMR factors was evaluated by hierarchical regressions. Fat mass-adjusted ANCOVA determined the interaction between PAEE and the C-HEI. In hierarchical regressions, the interaction PAEE $\times$ C-HEI was a correlate of more favourable values of HDL-C, apoB, apoA1:apoB and LDL-C:apoB ratios, and hs-CRP, while only PAEE was a negative correlate of haptoglobin. Compared with those in the low-PAEE/low-C-HEI group, women in the high-PAEE/highC-HEI group had 10\% higher HDL-C, 13\% lower apoB, $11 \%$ larger LDL particles and $28 \%$ lower hs-CRP concentrations $(P<0 \cdot 05)$. PAEE and the C-HEI have a synergistic association with the CMR profile. These results support the integration of both diet quality and physical activity in the management of CMR.

Key words: Inflammation: Physical activity energy expenditure: Healthy Eating Index: Diet quality: Obesity: Women

Obesity has reached pandemic proportions and is associated with several metabolic disorders including dyslipidaemia, insulin resistance and chronic subclinical inflammation, which all contribute to an increased risk of type 2 diabetes (T2D) and $\mathrm{CVD}^{(1)}$. Moreover, they are all components of cardiometabolic risk $(\mathrm{CMR})^{(2)}$. Interventions intended to prevent or delay the development of these chronic diseases (T2D and CVD) include lifestyle modifications focused on improving dietary habits, physical activity and weight management. Healthy diets are characterised by a high consumption of dietary fibres and PUFA, moderate alcohol consumption, and a low intake of red meat and sugar-sweetened beverages ${ }^{(3,4)}$. These diets are

Abbreviations: BP, blood pressure; C-HEI, Canadian Healthy Eating Index; CAO, Complications Associated with Obesity; CMR, cardiometabolic risk; CRP, C-reactive protein; EI, energy intake; hs-CRP, high-sensitivity C-reactive protein; HDL-C, HDL-cholesterol; HEI, Healthy Eating Index; HOMA-IR, homeostasis model assessment of insulin resistance; LDL-C, LDL-cholesterol; MONET, Montreal-Ottawa New Emerging Team; NHANES III, Third National Health and Nutrition Examination Survey; PAEE, physical activity energy expenditure; T2D, type 2 diabetes; TEE, total energy expenditure. 
associated with lower CMR as evidenced by a healthier plasma lipoprotein profile, glucose and inflammatory markers, as well as a lower incidence of the metabolic syndrome, T2D and CVD, independently of adiposity and physical activity ${ }^{(5-9)}$. While the latter studies have focused on specific aspects of the diet (i.e. specific nutrients), others have investigated the relationship between the overall diet quality, which is a reflection of the global effect of food intake, and CMR factors ${ }^{(10,11)}$.

The Healthy Eating Index (HEI) is a widely used diet quality index that evaluates the adherence of individuals to the US dietary intake recommendations ${ }^{(12)}$. A higher HEI is associated with lower BMI, C-reactive protein (CRP), glucose and glycated $\mathrm{Hb}$ $\left(\mathrm{HbA}_{1 \mathrm{C}}\right)$, as well as with a better endothelial function ${ }^{(10,13,14)}$. Similarly, independent of adiposity and energy intake (EI), high levels of physical activity are associated with a better plasma lipoprotein profile ${ }^{(15)}$ and lower subclinical inflammation ${ }^{(16)}$, the metabolic syndrome, T2D risk ${ }^{(17,18)}$ and mortality ${ }^{(19)}$.

We have recently shown that higher levels of physical activity energy expenditure (PAEE) are negatively associated with a better inflammatory profile (reduced serum concentration of CRP and haptoglobin) in overweight and obese sedentary postmenopausal women ${ }^{(16)}$. As previously stated by Joosten et al. ${ }^{(20)}$, healthy lifestyle behaviours (higher diet quality, physical activity and weight loss) 'are often intercorrelated and may be most effective when present in combination'. To our knowledge, there has been no report examining the effect of the combination of overall diet quality and physical activity on CMR factors in comparison with their effects taken separately. Therefore, the objective of the present study was to investigate whether diet quality, as assessed by the Canadian HEI (C-HEI), and PAEE have synergistic associations on a large panel of clinical and biochemical CMR factors in overweight and obese sedentary women. We hypothesised that higher PAEE in combination with higher diet quality would have a synergistic beneficial association with CMR factors than higher PAEE or higher diet quality alone.

\section{Subjects and methods}

\section{Subjects}

The cohort examined in the present cross-sectional a posteriori analysis was pooled from two hypoenergetic dietary intervention studies in similar populations. The two studies included non-diabetic overweight and obese postmenopausal women who were examined by our research team from 2003 to 2007: the Montreal-Ottawa New Emerging Team (MONET) Study $\left(n\right.$ 137) ${ }^{(21)}$ and the Complications Associated with Obesity (CAO) Study $\left(n\right.$ 59) ${ }^{(16)}$. Subjects from both studies were recruited through newspaper advertisements. The study was conducted according to the guidelines laid down in the Declaration of Helsinki and both studies were approved by the University of Montreal ethics committee. All subjects gave a written informed consent before the study started.

As described previously ${ }^{(16,21)}$, postmenopausal women were included in the two studies if they (1) had biological confirmation of the menopause status and were not on hormone replacement therapy, (2) had a BMI $\geq 27 \mathrm{~kg} / \mathrm{m}^{2}\left(30-40 \mathrm{~kg} / \mathrm{m}^{2}\right.$ for the CAO study), (3) aged between 46 and 70 years,
(4) were non-smokers and (5) were inactive $(<3 \mathrm{~h}$ of structured exercises per week for the CAO study and $<2 \mathrm{~h}$ for the MONET study). The exclusion criteria were as follows: (1) diabetes (fasting glucose $>7 \cdot 1 \mathrm{mmol} / 1$ or $2 \mathrm{~h}$ plasma glucose $>11 \cdot 1 \mathrm{mmol} / \mathrm{l}$ after a $75 \mathrm{~g}$ oral glucose tolerance test), (2) untreated thyroid disease, (3) chronic liver or renal disease, (4) asthma requiring therapy with steroids, (5) cardiovascular or peripheral vascular disease, (6) previous 3 months use of hormone replacement therapy, oestrogen, narcoleptics, steroids, or lipid-lowering or antihypertensive agents, (7) dyslipidaemia or hypertension requiring immediate medical intervention (total cholesterol $>8 \mathrm{mmol} / \mathrm{l}$, systolic blood pressure (BP) $>160 \mathrm{mmHg}$ or diastolic $\mathrm{BP}>100 \mathrm{mmHg}$ ), (8) history of alcohol or drug abuse, (9) abnormal blood laboratory values (haematocrit $<32$ or $>48 \%$; creatinine $>130 \mu \mathrm{mol} / \mathrm{l}$ ), (10) use of drugs or medications to stimulate weight loss, psychoactive drugs and adrenergic agonists by any route, (11) body-weight fluctuation $\pm 3 \mathrm{~kg}$ in the last 3 months $( \pm 2 \mathrm{~kg}$ for the MONET study and $\pm 3 \mathrm{~kg}$ for the CAO study) and (12) known history of inflammatory disease as well as cancer.

Of the 196 subjects recruited in the two studies, 124 subjects (eighty-eight from MONET study and thirty-six from CAO study) had a complete set of baseline data for all components of energy expenditure, cardiorespiratory fitness, dietary intake and CMR factors and were thus included in the present analysis.

\section{Diet quality}

For each $3 \mathrm{~d}$ food record, a score of diet quality was established using the index previously adapted for the Canadian population by Shatenstein $e t a l .^{(22)}$ : the C-HEI. It has a maximum score of 100 based on nine components: four major food groups assess the food guide servings (grain products, vegetables and fruits, milk products, and meat and alternatives, according to the 1997 Canada's Food Guide for Healthy Eating), three components assess total fat, saturated fat and cholesterol intake, one component assesses $\mathrm{Na}$ intake and one component assesses the variety of food consumed. The number of servings for each four food groups was calculated based on the information given by the 1997 Canada's Food Guide for Healthy Eating. Nutrient intake (total fat, saturated fat, cholesterol and $\mathrm{Na}$ ) was computed using the Food Processor SQL program (see the Covariates subsection). Each component is scored from 0 to 10, except for vegetables and fruits that scored from 0 to 20; all components are summed to yield a score between 0 and 100 . The criteria (minimum and maximum) followed to score each component of the C-HEI are presented in Table 1 . A score of 100 indicates that the dietary guidelines for the nine components have been fully met and a score of 0 indicates a complete lack of adherence.

\section{Energy expenditure and cardiorespiratory fitness}

Total energy expenditure (TEE) was assessed by doubly labelled water and resting energy expenditure (REE) was determined by indirect calorimetry, as described previously ${ }^{(23)}$. PAEE was calculated from the following equation ${ }^{(24)}$ :

$$
\mathrm{PAEE}=(\mathrm{TEE} \times 0.90)-\mathrm{REE},
$$


Table 1. Criteria used to establish the Canadian Healthy Eating Index score*

\begin{tabular}{|c|c|c|c|}
\hline Components $\dagger$ & Score range (points) & Criteria for maximum score, by ageł & Criteria for minimum score \\
\hline Intake of grain products & $0-10$ & $\begin{array}{l}\text { 18-49 years: } 9 \text { servings } \\
\geq 50 \text { years: } 6 \text { servings }\end{array}$ & 0 servings \\
\hline Intakes of vegetables and fruits & $0-20$ & $\begin{array}{l}18-49 \text { years: } 7 \text { servings } \\
\geq 50 \text { years: } 5 \text { servings }\end{array}$ & 0 servings \\
\hline Intakes of milk products & $0-10$ & 2 portions & 0 servings \\
\hline $\begin{array}{l}\text { Intakes of meat and } \\
\text { alternatives }\end{array}$ & $0-10$ & $\begin{array}{r}18-49 \text { years: } 2.5 \text { servings } \\
\geq 50 \text { years: } 2 \text { servings }\end{array}$ & 0 servings \\
\hline Total fat intake (\%) & $0-10$ & $<30 \%$ of energy from fat & $\geq 45 \%$ of energy from fat \\
\hline Saturated fat intake (\%) & $0-10$ & $<10 \%$ of energy from saturated fat & $\geq 15 \%$ of energy from saturated fat \\
\hline Cholesterol intake & $0-10$ & $\leq 300 \mathrm{mg}$ & $\geq 450 \mathrm{mg}$ \\
\hline Dietary $\mathrm{Na}$ intake & $0-10$ & $\leq 2400 \mathrm{mg}$ & $\geq 4800 \mathrm{mg}$ \\
\hline Diversity & $0-10$ & $\begin{array}{l}\geq 1 \text { servings from each of four food } \\
\text { groups of the CFGHE }\end{array}$ & $\begin{array}{l}<1 \text { serving from each of four food } \\
\text { groups of the CFGHE }\end{array}$ \\
\hline
\end{tabular}

CFGHE, Canada's Food Guide for Healthy Eating.

* Adapted from Shatenstein et al. ${ }^{(22)}$

†The first four components are based on the 1997 CFGHE; evaluation considers daily intakes.

$\ddagger$ Proportional scores are computed for intakes situated between the maximum and minimum criteria.

where thermic effect of food was assumed as $10 \%$ of $\mathrm{TEE}^{(25)}$.

Cardiorespiratory fitness $\left(\mathrm{VO}_{2}\right.$ peak) was assessed by a graded exercise test on an ergocycle Ergoline 900 (Ergoline), as described previously ${ }^{(16)}$. Briefly, the highest value obtained during the test was considered as the peak $\mathrm{VO}_{2}$ (litres/min). That value was then divided by the body weight to give the relative $\mathrm{VO}_{2}$ peak (litres/min per $\mathrm{kg}$ ). Expired gas was analysed during the exercise protocol using an Ergocard (software version 6; MediSoft) cardiopulmonary exercise test station. A successful $\mathrm{VO}_{2}$ peak was obtained when three of the following criteria were reached: respiratory exchange ratio above $1 \cdot 1$; heart rate within 10 beats/min of the maximal predicted heart rate value ( 220 - age); volitional cessation of exercise by the subject; plateau in oxygen consumption for $60 \mathrm{~s}$.

\section{Cardiometabolic risk factors}

Venous blood samples were collected at baseline before a $75 \mathrm{~g}$ oral glucose tolerance test and every $30 \mathrm{~min}$ for $2 \mathrm{~h}$ thereafter. Measurements of fasting insulin levels were analysed by RIA specific for human insulin (Linco), fasting glucose, plasma total cholesterol, HDL-cholesterol (HDL-C) and TAG on the Cobas Integra 400 (Roche Diagnostic), and apoA1 and apoB by immunonephelometry on an Image analyser (Beckman Coulter). LDL-cholesterol (LDL-C) was calculated according to the Friedewald equation ${ }^{(26)}$. Non-HDL-C and total cholesterol:HDL-C were also calculated. The size of LDL particles was estimated as the LDL-C:apoB ratio ${ }^{(27)}$.

Insulin sensitivity was estimated using the fasting homeostasis model assessment (HOMA-IR) according to the formula of Matthews et $a l{ }^{(28)}$. Insulin sensitivity was also determined by measuring the glucose disposal rate during a hyperinsulinaemic-euglycaemic clamp, as described previously ${ }^{(29)}$. Glucose disposal rates during the clamp were expressed as $\mathrm{mg} / \mathrm{min}$ per kg fat-free mass.

Serum high-sensitivity CRP (hs-CRP), orosomucoid and haptoglobin were assessed by immunonephelometry on an Image analyser (Beckman Coulter), IL-6 was measured using highsensitivity commercial ELISA kits (Quantikine) and leucocyte count was assessed in an automated cell counter using an $\mathrm{A}^{\mathrm{C}} \cdot \mathrm{T} 5$ diff $\mathrm{AL}$ analyser (Beckman Coulter). In the present study, four women with hs-CRP $>10 \mathrm{mg} / \mathrm{l}$ were excluded from the analysis as such an elevated hs-CRP suggests an acute inflammatory state ${ }^{(30)}$.

Sitting BP was determined after the subjects had rested quietly for 10 min, using a Dinamap automatic machine (Welch Allyn).

\section{Covariates}

Body weight was measured to the nearest $0 \cdot 1 \mathrm{~kg}$ using a calibrated scale (Balance Industrielle Montréal) and subjects' height was measured with a standard stadiometer (Perspective Enterprises). Then, BMI was calculated as body weight $(\mathrm{kg}) /$ height $\left(\mathrm{m}^{2}\right)^{(31)}$. Measurements of total lean body mass and fat mass were done by dual-energy X-ray absorptiometry with a LUNAR Prodigy system (software version 6.10.019; General Electric Lunar Corporation), while visceral adipose tissue (VAT) and subcutaneous adipose tissue were measured by abdominal computed tomography scan (General Electric Medical Systems), as described previously $^{(16,21)}$

Food and nutrient intakes were assessed with a $3 \mathrm{~d}$ food record at baseline, during a weight stabilisation period, as described previously ${ }^{(32)}$. Briefly, subjects were instructed by a registered dietitian on how to record food intake, including condiments and beverages, over two weekdays and one weekend day while maintaining their usual habits. Analyses were conducted with the Food Processor SQL program (Food Processor SQL Edition, version 9.6.2, 2004; ESHA Research), using the 2001 Canadian Nutrient Data File and the US Department of Agriculture database (when foods were not available in the Canadian Nutrient Data File). Mean intake of $3 \mathrm{~d}$ for energy from total and saturated fat, cholesterol and $\mathrm{Na}$ intake was calculated for each subject.

\section{Identification of energy intake in under-reporting subjects}

The ratio of reported EI:TEE (EI:TEE) was used to identify subjects who under- or over-reported their EI. The cut-off point of EI:TEE $<0.80$ was used to identify subjects who under-reported their EI, as described previously by Black \& 
Cole ${ }^{(33)}$. Subjects with a ratio of EI:TEE $>1 \cdot 20$ were identified as over-reporters, as reported previously ${ }^{(34)}$, and those with a ratio between 0.80 and 1.20 were considered as normal reporters.

\section{Statistical analysis}

The synergistic associations of PAEE and the C-HEI with clinical and biochemical CMR factors were determined using hierarchical regressions. This test allows the selection of independent variables from one group (or bloc) of variables at a time using a stepwise approach. The selection of variables in bloc 2 does not affect the variables selected from bloc 1 ; the selected variables of bloc 1 are kept in the model. In the final model, all variables selected in each bloc become part of the model even if they are no longer significant. In our hierarchical regression analyses, CMR factors were entered as dependent variables and independent variables were entered in the models as follow: bloc 1 (stepwise) included BMI, total fat mass and VAT to control for the potential effect of body composition on the relationships between PAEE/C-HEI and CMR factors, and bloc 2 (stepwise) included PAEE, C-HEI and their interaction (PAEE $\times$ C-HEI), adjusted to the mean. This step (adjusted to the mean) was achieved as follows: 'individual value' minus the mean of the cohort. These calculations were done for PAEE and C-HEI variables. The interaction term, PAEE $\times$ C-HEI, was calculated as follows: PAEE (adjusted to the mean) $\times$ C-HEI (adjusted to the mean). This approach stabilised the regression models. We also reran the hierarchical regression analysis with the addition of $\mathrm{EI}$ and age as independent variables in bloc 1 to determine their potential effect on the synergistic associations between PAEE and the C-HEI with CMR factors. HOMA-IR, IL-6 and hsCRP were log-transformed in the hierarchical regression because they were not normally distributed.

The magnitude of the synergistic associations between PAEE and the C-HEI with CMR factors was further determined by dividing the subjects into four groups according to their PAEE levels and C-HEI score (high and/or low levels of PAEE and the $\mathrm{C}$-HEI). The median of the whole cohort for PAEE and the C-HEI was used as cut-off points (median of PAEE $=4008 \mathrm{~kJ} / \mathrm{d}$ $(958 \mathrm{kcal} / \mathrm{d})$, median of the $\mathrm{C}-\mathrm{HEI}=83 \cdot 3)$. ANOVA was used to compute raw means of PAEE, C-HEI, anthropometric parameters and CMR factors by PAEE and C-HEI groups and to identify pairwise mean differences among the groups.

ANCOVA adjusted for total fat mass (or BMI, for clinical relevance, or VAT instead of fat mass) was used to calculate least square means of CMR factors identified as significant correlates of PAEE $\times$ C-HEI (HDL-C, apoB, hs-CRP, apoA1:apoB and LDL-C:apoB) in the hierarchical regression and to compute pairwise mean differences among the PAEE/C-HEI groups. As for the hierarchical regressions, hs-CRP was log-transformed in the ANCOVA analyses because it was not normally distributed. In secondary analyses, the ANCOVA models were additionally adjusted for age and EI. The percentage of the difference between the low-PAEE/low-C-HEI group and the three other groups for HDL-C, apoB and hs-CRP concentrations and the ratios apoA1:apoB and LDL-C:apoB were calculated as follows:

\author{
Percentage difference \\ $=$ (individual data - mean of the low-PAEE $/$ \\ low-C-HEI group)/mean of the low-PAEE/ \\ low-C-HEI group $\times 100$,
}

where the 'individual data' represent the value of each subject of the three other groups (low-PAEE/high-C-HEI, high-PAEE/ low-C-HEI and high-PAEE/high-C-HEI) for HDL-C, apoB, hs-CRP, apoA1:apoB or LDL-C:apoB variables.

Considering the importance of under-reporting EI in overweight and obese individuals ${ }^{(34)}$, differences in C-HEI scores between under- and over-reporters with normal reporters were determined using unpaired Student's $t$ test.

Data are presented as means and standard deviations for continuous variables and as percentages (with error bars representing standard deviations) for categorical variables. All statistical analyses were performed using Statistical Package for the Social Sciences software (version 17.0.1, 2008; SPSS) and significance was set at $P<0.05$ (two-sided).

\section{Results}

\section{Characteristics of the cohort}

As shown in Table 2, women included in the present analysis had a mean age of 58 (SD 5) years and a mean BMI of 33.0 (SD 4.6) $\mathrm{kg} / \mathrm{m}^{2}$, with thirty-four women having a BMI between 27 and $<30 \mathrm{~kg} / \mathrm{m}^{2}$ and ninety women having a BMI $\geq 30 \mathrm{~kg} / \mathrm{m}^{2}$. Values for glycaemia, blood lipids and BP were within the normal range. The mean C-HEI score for the whole cohort was 83.2 (SD 0.8 ) with $64.5 \%$ of the women having a diet quality classified as 'good' (C-HEI score $>80$ ), 35.5\% having a 'needs improvement' diet (C-HEI score 51-80) and none having a 'poor' diet (C-HEI score $<51$ ). The mean score for each component of the C-HEI score is presented in Fig. 1. Because of the large number of subjects $(>69 \%)$ meeting the recommended intake for four out of nine components of the C-HEI index (vegetables and fruits $76.6 \%$; meats and alternatives $79.0 \%$; cholesterol $69.4 \%$; dietary variety $77.4 \%$ ), we used only the total C-HEI score in further analyses. The mean PAEE of the whole cohort was 3976 (sD 1266) kJ/d (950 (sD 303) kcal/d) (Table 2) with a wide range of values $(824-7100 \mathrm{~kJ} / \mathrm{d}(197-1697 \mathrm{kcal} / \mathrm{d}))$.

\section{Associations between the physical activity energy expenditure $\times$ Canadian Healthy Eating Index interaction with cardiometabolic risk factors}

In hierarchical regression analyses, the interaction PAEE $\times$ C-HEI and VAT explained $13 \%$ of the variance observed in HDL-C $(P<0 \cdot 005)$, while PAEE $\times$ C-HEI, BMI and VAT explained $24 \%$ of the variance in log hs-CRP $(P<0.05)$ (Table 3$)$. Furthermore, the interaction PAEE $\times$ C-HEI was the only correlate of apoB $(P<0.01)$, LDL-C:apoB $(P<0 \cdot 01)$ and apoA1:apoB $(P<0 \cdot 01)$ levels. PAEE independently predicted the interindividual variance in haptoglobin $(P<0.05)$, while the C-HEI was not associated with any of the CMR factors. Total fat mass was an independent correlate of total cholesterol, resting diastolic BP and orosomucoid $(P<0 \cdot 05)$. BMI independently explained 
Table 2. Raw means of cardiometabolic risk factors, energy expenditure and cardiorespiratory fitness among the physical activity energy expenditure (PAEE)/Canadian Healthy Eating Index (C-HEI) groups

(Mean values and standard deviations)

\begin{tabular}{|c|c|c|c|c|c|c|c|c|c|c|}
\hline \multirow[b]{2}{*}{ Characteristics } & \multicolumn{2}{|c|}{ Total $(n 124)$} & \multicolumn{2}{|c|}{$\begin{array}{l}\text { Low PAEE/low } \\
\text { C-HEI ( } n \text { 33) }\end{array}$} & \multicolumn{2}{|c|}{$\begin{array}{l}\text { Low PAEE/high } \\
\text { C-HEI }(n 29)\end{array}$} & \multicolumn{2}{|c|}{$\begin{array}{l}\text { High PAEE/low } \\
\text { C-HEI ( } n \text { 29) }\end{array}$} & \multicolumn{2}{|c|}{$\begin{array}{l}\text { High PAEE/high } \\
\text { C-HEI }(n 33)\end{array}$} \\
\hline & Mean & SD & Mean & SD & Mean & SD & Mean & SD & Mean & SD \\
\hline PAEE (kcal/d) & 950 & 303 & 698 & 175 & 707 & 163 & $1170^{\star \dagger}$ & 187 & $1223^{\star \dagger}$ & 166 \\
\hline PAEE $(\mathrm{kJ} / \mathrm{d})$ & 3976 & 1266 & 2920 & 732 & 2957 & 684 & $4894^{\star \dagger}$ & 782 & $5119^{* \dagger}$ & 696 \\
\hline C-HEI & 83.2 & $9 \cdot 2$ & $76 \cdot 8$ & 5.9 & $90 \cdot 3^{\star \ddagger}$ & 3.6 & $74 \cdot 3$ & $7 \cdot 0$ & $91 \cdot 0^{\star \ddagger}$ & $3 \cdot 6$ \\
\hline Age (years) & $57 \cdot 7$ & $4 \cdot 7$ & $58 \cdot 0$ & 4.5 & $58 \cdot 7$ & $4 \cdot 7$ & $56 \cdot 6$ & 4.8 & 57.5 & 4.9 \\
\hline \multicolumn{11}{|l|}{ Anthropometric parameters } \\
\hline Body weight $(\mathrm{kg})$ & $86 \cdot 7$ & 14.9 & $86 \cdot 5$ & $15 \cdot 9$ & 83.0 & $14 \cdot 1$ & 91.5 & $15 \cdot 4$ & $86 \cdot 0$ & 13.5 \\
\hline $\operatorname{BMI}\left(\mathrm{kg} / \mathrm{m}^{2}\right)$ & 33.0 & 4.6 & 32.5 & 4.7 & $31 \cdot 8$ & 3.9 & $35 \cdot 1$ & $5 \cdot 0$ & $32 \cdot 8$ & $4 \cdot 2$ \\
\hline Total fat mass $(\mathrm{kg})$ & $40 \cdot 2$ & 9.9 & 40.5 & $10 \cdot 0$ & $37 \cdot 2$ & $8 \cdot 8$ & 43.7 & $9 \cdot 8$ & 39.7 & $10 \cdot 1$ \\
\hline Total lean body mass $(\mathrm{kg})$ & 43.4 & $6 \cdot 6$ & $42 \cdot 6$ & 6.9 & $42 \cdot 7$ & $7 \cdot 1$ & 44.8 & 7.5 & 43.5 & 4.9 \\
\hline VAT $\left(\mathrm{cm}^{2}\right)$ & 190 & 52 & 189 & 44 & 180 & 47 & 200 & 61 & 189 & 54 \\
\hline SAT $\left(\mathrm{cm}^{2}\right)$ & 484 & 123 & 486 & 120 & 439 & 109 & 530 & 117 & 482 & 133 \\
\hline Systolic BP (mmHg) & 123 & 14 & 124 & 13 & 123 & 14 & 122 & 16 & 122 & 11 \\
\hline Diastolic BP (mmHg) & 77 & 8 & 78 & 7 & 76 & 10 & 77 & 9 & 77 & 7 \\
\hline \multicolumn{11}{|l|}{ Blood lipids and lipoproteins } \\
\hline Total cholesterol $(\mathrm{mmol} / \mathrm{l})$ & $5 \cdot 35$ & 0.82 & $5 \cdot 39$ & 0.74 & $5 \cdot 28$ & 0.94 & $5 \cdot 16$ & 0.79 & 5.53 & 0.78 \\
\hline $\mathrm{HDL}-\mathrm{C}(\mathrm{mmol} / \mathrm{l})$ & 1.45 & 0.34 & 1.43 & 0.29 & 1.39 & 0.34 & 1.38 & 0.29 & $1.58^{\dagger \ddagger}$ & 0.38 \\
\hline LDL-C $(\mathrm{mmol} / \mathrm{l})$ & 3.15 & 0.70 & $3 \cdot 17$ & 0.67 & 3.08 & 0.71 & 3.05 & 0.67 & $3 \cdot 28$ & 0.75 \\
\hline $\mathrm{TAG}(\mathrm{mmol} / \mathrm{l})$ & 1.64 & 0.78 & 1.66 & 0.78 & 1.85 & 0.95 & 1.60 & 0.75 & 1.47 & 0.62 \\
\hline Total cholesterol:HDL-C & 3.83 & 0.86 & $3 \cdot 88$ & 0.86 & 3.90 & 0.81 & 3.84 & 0.76 & 3.71 & 1.02 \\
\hline Non-HDL-C (mmol/l) & 3.90 & 0.79 & 3.95 & 0.75 & 3.89 & 0.83 & 3.78 & 0.70 & 3.96 & 0.88 \\
\hline apoB $(g / l)$ & 0.99 & 0.21 & 1.04 & 0.21 & 1.01 & 0.23 & 0.99 & $0 \cdot 18$ & $0.94^{*}$ & 0.21 \\
\hline apoA1 (g/l) & 1.44 & 0.23 & 1.45 & 0.17 & 1.40 & 0.21 & 1.41 & 0.22 & 1.51 & 0.28 \\
\hline LDL-C:apoB & $3 \cdot 20$ & 0.57 & 3.07 & 0.48 & 3.05 & 0.38 & 3.11 & 0.61 & $3.53^{* \dagger \ddagger}$ & 0.64 \\
\hline apoA1:apoB & 1.52 & 0.43 & 1.45 & 0.36 & 1.45 & 0.38 & 1.46 & 0.34 & $1 \cdot 70^{\star \dagger \ddagger}$ & 0.56 \\
\hline \multicolumn{11}{|l|}{ Glucose homeostasis } \\
\hline Fasting glycaemia $(\mathrm{mmol} / \mathrm{l})$ & $5 \cdot 24$ & 0.54 & $5 \cdot 35$ & 0.57 & 5.28 & 0.48 & $5 \cdot 07^{\star}$ & 0.49 & $5 \cdot 26$ & 0.57 \\
\hline Fasting insulin $(\mathrm{pmol} / \mathrm{l})$ & $109 \cdot 0$ & $49 \cdot 3$ & $108 \cdot 2$ & $37 \cdot 8$ & $107 \cdot 5$ & 48.9 & $117 \cdot 0$ & $72 \cdot 3$ & $104 \cdot 1$ & 33.9 \\
\hline Glucose disposal rate $(\mathrm{mg} / \mathrm{kg}$ per $\mathrm{min}) \S$ & 11.5 & 3.6 & 11.6 & 3.5 & $10 \cdot 7$ & $3 \cdot 1$ & 11.6 & 4.4 & $12 \cdot 2$ & $3 \cdot 3$ \\
\hline HOMA-IR & 3.7 & 1.9 & 3.8 & 1.5 & 3.7 & $2 \cdot 0$ & 3.8 & $2 \cdot 6$ & 3.5 & 1.3 \\
\hline \multicolumn{11}{|l|}{ Inflammatory markers } \\
\hline $\mathrm{IL}-6(\mathrm{pg} / \mathrm{ml})$ & 1.46 & 0.94 & 1.60 & 1.00 & 1.29 & 0.64 & 1.48 & 0.67 & 1.45 & 1.30 \\
\hline hs-CRP (mg/l)\| & 2.95 & 2.08 & $3 \cdot 18$ & 17.99 & $2 \cdot 70$ & 14.54 & 3.37 & $18 \cdot 15$ & 2.53 & $13 \cdot 86$ \\
\hline Orosomucoid (g/l) & 0.85 & 0.19 & 0.86 & 0.22 & 0.87 & 0.20 & 0.87 & 0.17 & 0.81 & 0.16 \\
\hline Haptoglobin $(\mathrm{g} / \mathrm{l})$ & 1.33 & 0.48 & 1.50 & 0.56 & 1.36 & 0.47 & 1.27 & 0.42 & $1 \cdot 18^{*}$ & 0.39 \\
\hline Leucocyte count $\left(\times 10^{9} / /\right)$ & $5 \cdot 86$ & 1.38 & $5 \cdot 72$ & 1.30 & $5 \cdot 84$ & 1.42 & $6 \cdot 18$ & 1.27 & 5.73 & 1.56 \\
\hline \multicolumn{11}{|l|}{ Energy expenditure } \\
\hline TEE (kcal/d) & 2550 & 418 & 2260 & 288 & 2252 & 321 & $2840^{\dagger}$ & 349 & $2846^{\dagger}$ & 237 \\
\hline TEE $(\mathrm{kJ} / \mathrm{d})$ & 10670 & 1747 & 9458 & 1203 & 9424 & 1345 & $11885^{\star \dagger}$ & 1461 & $11912^{\star \dagger}$ & 993 \\
\hline REE (kcal/d) & 1345 & 205 & 1336 & 225 & 1320 & 202 & 1387 & 225 & 1339 & 167 \\
\hline $\operatorname{REE}(\mathrm{kJ} / \mathrm{d})$ & 5628 & 856 & 5992 & 942 & 5524 & 845 & 5803 & 942 & 5602 & 700 \\
\hline $\mathrm{VO}_{2}$ peak $(\mathrm{ml} / \mathrm{min}$ per $\mathrm{kg})$ & $17 \cdot 1$ & $3 \cdot 6$ & $16 \cdot 1$ & 4.0 & $17 \cdot 6$ & $4 \cdot 4$ & $17 \cdot 0$ & $2 \cdot 8$ & $17 \cdot 8$ & $2 \cdot 8$ \\
\hline
\end{tabular}

VAT, visceral adipose tissue; SAT, subcutaneous adipose tissue; BP, blood pressure; HDL-C, HDL-cholesterol; LDL-C, LDL-cholesterol; HOMA-IR, homeostasis model assessment of insulin resistance; hs-CRP, high-sensitivity C-reactive protein; TEE, total energy expenditure; $\mathrm{REE}$, resting energy expenditure; $\mathrm{VO}_{2} \mathrm{Peak}$, cardiorespiratory fitness.

* Mean values were significantly different from those of the low-PAEE/low-C-HEI group $(P<0.05$; ANOVA).

$\dagger$ Mean values were significantly different from those of the low-PAEE/high-C-HEI group $(P<0.05 ;$ ANOVA).

$\ddagger$ Mean values were significantly different from those of the high-PAEE/low-C-HEl group $(P<0.05 ;$ ANOVA $)$.

§ Glucose disposal rate calculated from the hyperinsulinaemic-euglycaemic clamp.

\|I $n 120$ in the whole cohort, $n 32$ in the low-PAEE/low-C-HEI group, $n 29$ in the low-PAEE/high-C-HEI and high-PAEE/low-C-HEI groups, $n$ 30 in the high-PAEE/high-C-HEI group.

$18 \%$ of the variance in IL-6 $(P<0 \cdot 001)$, while VAT was an independent correlate of total cholesterol:HDL-C $(P<0.05)$, resting systolic BP $(P<0.05)$, fasting insulin $(P<0.001)$, log HOMA-IR $(P<0.001)$, glucose disposal rate $(P<0.01)$ and leucocyte count $(P<0 \cdot 01)$. Both VAT and BMI were independent correlates of fasting glycaemia $(P<0 \cdot 05)$. LDL-C and non-HDL-C were not associated with any of the independent variables included in the model. Additional adjustment for EI and age did not alter the primary findings (see Supplemental Table 1 of the supplementary material; available online at http://www.journals.cambridge.org/bjn), with the exception of orosomucoid for which VAT became a correlate instead of total fat mass $(P=0 \cdot 044)$. These two variables were not predictors of any of the CMR factors.

Results of ANOVA showed no differences among the four PAEE/C-HEI groups for age, anthropometric measures and systolic and diastolic BP (Table 2). As expected, women in the two high-PAEE groups had higher levels of TEE $(P<0 \cdot 05)$, while no difference was observed for resting energy expenditure and cardiorespiratory fitness among the groups (Table 2). In fat massadjusted ANCOVA analyses, women in the high-PAEE/high-CHEI group had the highest concentrations of HDL-C and levels of LDL-C:apoB and apoA1:apoB, and the lowest levels 


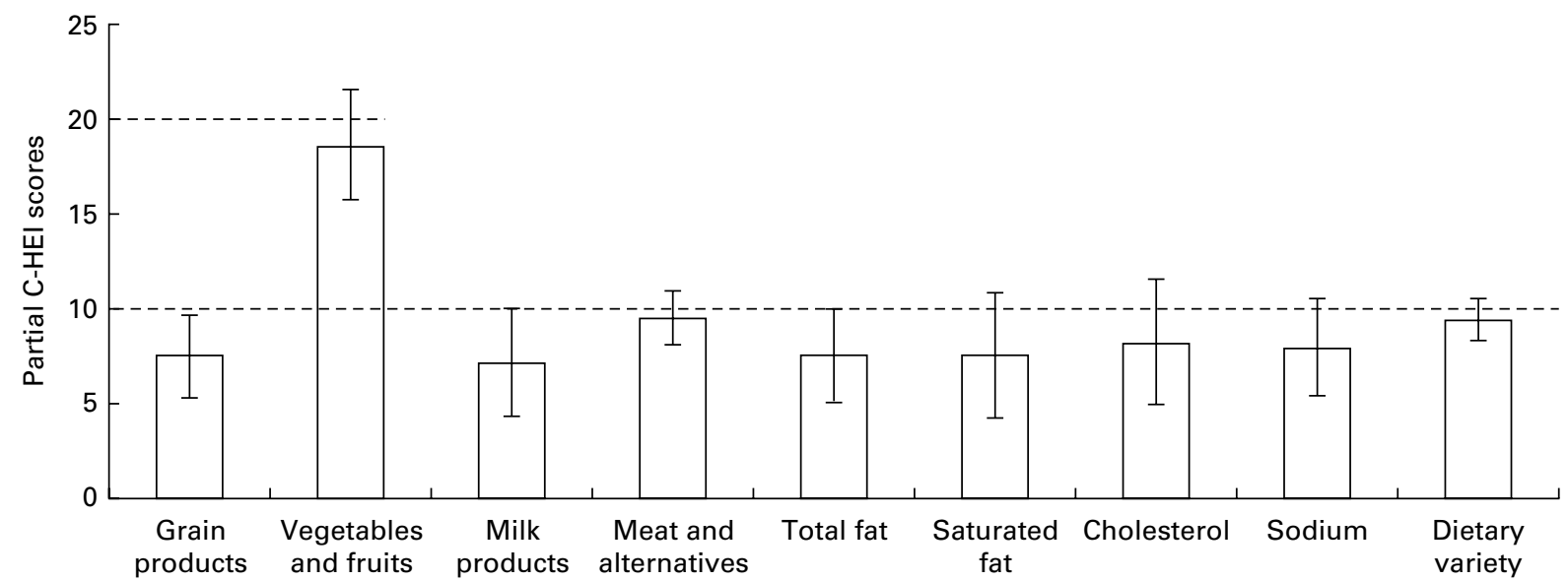

Fig. 1. Scores of the components of the Canadian Healthy Eating Index (C-HEI) in the whole cohort. Values are means, with standard deviations represented by vertical bars. The dashed lines represent the maximum score for each component.

of apoB and log hs-CRP ( $P<0.05$; Table 4). Adjustment of ANCOVA for BMI or VAT instead of fat mass resulted in similar differences among the groups, except for hs-CRP for which the adjustment of ANCOVA for BMI removed the difference between the high-PAEE/low-C-HEI and high-PAEE/high-CHEI groups (data not shown). Moreover, further adjustments for age and EI (in addition to fat mass (or BMI)) did not affect the results (data not shown).

As shown in Fig. 2, compared with those in the low-PAEE/ low-C-HEI groups, women in the high-PAEE/high-C-HEI group had higher levels of HDL-C by $10 \%$, LDL-C:apoB by $11 \%$ and apoA 1 apoB by $14 \%$, and lower levels of apoB by $13 \%$ and hs-CRP by $28 \%$. There was no statistical difference between women in the low-PAEE/low-C-HEI group with the two other groups for these five CMR factors.

\section{Comparison of diet quality scores in under-, normal and over-reporters}

In our cohort, seventy-three women were characterised as under-reporters, forty-four were normal reporters and seven were over-reporters. The mean C-HEI score of the under-reporters (83.8 (SD 9.3)) and the over-reporters (76.0 (SD 11.6)) were not different from that of the normal reporters (83.3 (SD 8.3)) (under- $v$. normal reporters: $P=0 \cdot 76$; over- $v$. normal reporters: $P=0 \cdot 10)$.

Table 3. Hierarchical regression analysis on the association between cardiometabolic risk factors and physical activity energy expenditure (PAEE), Canadian Healthy Eating Index $(\mathrm{C}-\mathrm{HEI})$ and their interaction $(\mathrm{PAEE} \times \mathrm{C}-\mathrm{HEI})^{\star}$

\begin{tabular}{|c|c|c|c|c|c|c|}
\hline Dependent variable & Step & Independent variable & Constant & Coefficient & Total $R^{2}$ & $P$ \\
\hline Total cholesterol & 1 & Total fat mass & $6 \cdot 117$ & -0.019 & 0.054 & 0.011 \\
\hline HDL-C & $\begin{array}{l}1 \\
2\end{array}$ & $\begin{array}{l}\text { VAT } \\
\text { PAEE } \times \mathrm{C}-\mathrm{HEI}\end{array}$ & 1.822 & $\begin{array}{l}-0.002 \\
2.289 \times 10^{-6}\end{array}$ & 0.128 & $\begin{array}{l}0.001 \\
0.034\end{array}$ \\
\hline Total cholesterol:HDL-C & 1 & VAT & 3.204 & 0.003 & 0.039 & 0.028 \\
\hline apoB & 1 & PAEE $\times$ C-HEI & 0.993 & $-1.979 \times 10^{-6}$ & 0.066 & 0.004 \\
\hline LDL-C:apoB & 1 & PAEE $\times \mathrm{C}-\mathrm{HEI}$ & 3.205 & $6.695 \times 10^{-6}$ & 0.100 & $<0.001$ \\
\hline apoA1 & 1 & VAT & 1.622 & -0.001 & 0.046 & 0.017 \\
\hline apoA1:apoB & 1 & PAEE $\times$ C-HEI & 1.524 & $4.281 \times 10^{-6}$ & 0.070 & 0.003 \\
\hline Systolic BP & 1 & VAT & 111.571 & 0.059 & 0.049 & 0.031 \\
\hline Diastolic BP & 1 & Total fat mass & $70 \cdot 516$ & $0 \cdot 161$ & 0.038 & 0.031 \\
\hline \multirow[t]{2}{*}{ Fasting glycaemia } & 1 & VAT & \multirow[t]{2}{*}{$5 \cdot 329$} & 0.004 & \multirow[t]{2}{*}{0.105} & $<0.001$ \\
\hline & 2 & BMI & & -0.025 & & 0.035 \\
\hline Fasting insulinaemia & 1 & VAT & $2 \cdot 777$ & 0.068 & 0.242 & $<0.001$ \\
\hline Log HOMA-IR & 1 & VAT & 0.193 & 0.002 & 0.230 & $<0.001$ \\
\hline Glucose disposal rate & 1 & VAT & 14.797 & -0.017 & 0.059 & 0.007 \\
\hline Log IL-6 & 1 & BMI & -0.624 & 0.022 & 0.176 & $<0.001$ \\
\hline \multirow[t]{3}{*}{ Log hs-CRP } & 1 & BMI & \multirow{3}{*}{-7.727} & 0.027 & \multirow{3}{*}{0.242} & $<0.001$ \\
\hline & 2 & VAT & & 0.001 & & 0.059 \\
\hline & 3 & PAEE $\times$ C-HEI & & $-2.046 \times 10^{-6}$ & & 0.041 \\
\hline Orosomucoid & 1 & Total fat mass & 0.696 & 0.004 & 0.041 & 0.025 \\
\hline Haptoglobin & 1 & PAEE & $1 \cdot 329$ & 0.000 & 0.054 & 0.010 \\
\hline Leucocyte count & 1 & VAT & 4.468 & 0.007 & 0.077 & 0.002 \\
\hline
\end{tabular}

HDL-C, HDL-cholesterol; VAT, visceral adipose tissue; LDL-C, LDL-cholesterol; BP, blood pressure; HOMA-IR, homeostasis model assessment of insulin resistance; hs-CRP, high-sensitivity C-reactive protein.

*Independent variables included in the model: bloc 1 (stepwise) - BMI, total fat mass and VAT; bloc 2 (stepwise) - PAEE (adjusted to the mean), C-HEI (adjusted to the mean) and PAEE $\times$ C-HEI (adjusted to the mean). 
Table 4. Adjusted means of cardiometabolic risk factors among the physical activity energy expenditure (PAEE)/Canadian Healthy Eating Index (C-HEI) groups

(Mean values and standard deviations)

\begin{tabular}{|c|c|c|c|c|c|c|c|c|}
\hline \multirow[b]{2}{*}{ Characteristics } & \multicolumn{2}{|c|}{$\begin{array}{c}\text { Low PAEE/low } \\
\text { C-HEI ( } n 33)\end{array}$} & \multicolumn{2}{|c|}{$\begin{array}{l}\text { Low PAEE/high } \\
\text { C-HEI ( } n \text { 29) }\end{array}$} & \multicolumn{2}{|c|}{$\begin{array}{l}\text { High PAEE/low } \\
\text { C-HEI (n 29) }\end{array}$} & \multicolumn{2}{|c|}{$\begin{array}{l}\text { High PAEE/high } \\
\text { C-HEI ( } n 33)\end{array}$} \\
\hline & Mean & SD & Mean & SD & Mean & SD & Mean & SD \\
\hline HDL-C & 1.43 & 0.06 & 1.37 & 0.06 & $1.40^{\dagger}$ & 0.06 & $1.57^{\dagger \ddagger}$ & 0.06 \\
\hline apoB & 1.04 & 0.04 & 1.00 & 0.04 & 1.00 & 0.04 & $0.94^{*}$ & 0.04 \\
\hline LDL-C:apoB & 3.07 & 0.09 & 3.05 & 0.10 & $3 \cdot 12$ & $0 \cdot 10$ & $3.53^{\star}+\ddagger$ & $0 \cdot 10$ \\
\hline apoA1:apoB & 1.45 & 0.07 & 1.45 & 0.08 & 1.46 & 0.08 & $1 \cdot 70^{\star \dagger \ddagger}$ & 0.08 \\
\hline Log hs-CRP§ & 0.39 & 0.05 & 0.37 & 0.06 & 0.43 & 0.06 & $0.26^{\ddagger}$ & 0.06 \\
\hline
\end{tabular}

HDL-C, HDL-cholesterol; LDL-C, LDL-cholesterol; hs-CRP, high-sensitivity C-reactive protein.

* Mean values were significantly different from those of the low-PAEE/low-C-HEI group $(P<0.05 ;$ ANCOVA $)$

${ }^{\dagger}$ Mean values were significantly different from those of the low-PAEE/high-C-HEI group $(P<0.05$; ANCOVA).

¥ Mean values were significantly different from those of the high-PAEE/low-C-HEI group $(P<0.05 ;$ ANCOVA $)$.

$\S n 32$ in the low-PAEE/low-C-HEI group and $n 30$ in the high-PAEE/high-C-HEI group.

\section{Discussion}

The main results from the present study show that the combination of higher diet quality and PAEE has modest but significant synergistic associations with the blood lipoprotein profile (HDL-C, apoB, apoA1:apoB and LDL-C:apoB) and subclinical inflammation (hs-CRP) in women even after adjustments for adiposity.

Accumulating evidence from interventional studies indicates that the adoption of a healthy diet and an active lifestyle, as well as weight loss, can improve the blood lipoprotein profile, glucose tolerance and subclinical inflammation, which reduce the risk for T2D ${ }^{(35-38)}$. For example, in the Diabetes Prevention Program, subjects with impaired glucose tolerance reduced their risk for T2D either by losing body weight, while keeping their sedentary lifestyle, or by improving physical activity, without any significant weight $\operatorname{loss}^{(18)}$. A few studies have investigated the separate effect of these lifestyle behaviours (diet, physical activity and weight loss) in comparison with their combination on the risk for T2 $\mathrm{D}^{(18,37,39)}$. No significant effect of dietary modifications alone on T2D incidence has been reported in two of them ${ }^{(18,37)}$. Despite the cross-sectional design of the present study, the present results suggest that improving both diet quality and physical activity is associated with lower CMR (i.e. better blood lipoprotein profile and lower CRP) than improving either factor alone, independently of the level of adiposity. However, it should be noted that although a large panel of clinical and biochemical CMR factors were measured in the present study, some other important factors were not measured (e.g. socio-economic and psychological status). Nevertheless, the present findings suggest that a reduction in the development of obesity-related cardiometabolic complications in an obese but otherwise relatively healthy population may be possible with improvement in diet quality and physical activity, independently of adiposity. Further investigations using high-risk individuals for $\mathrm{T} 2 \mathrm{D}$ and $\mathrm{CHD}$ are required to validate this hypothesis.

Kraus et al. ${ }^{(15)}$ reported that physical activity was associated with favourable changes in the lipoprotein profile in sedentary overweight individuals. However, no association has been reported between diet quality (assessed by the original HEI), and total cholesterol, HDL-C and LDL-C ${ }^{(14,40,41)}$. To our knowledge, no study has investigated the association between diet quality and the number or size of atherogenic lipoproteins. We have previously reported that postmenopausal overweight and obese sedentary women with higher levels of PAEE have lower concentrations of inflammatory markers as well as healthier lipoprotein and blood lipid profiles (lower levels of TAG and apoB; larger LDL size) ${ }^{(16)}$. Here we have further reported that women in the high-PAEE/high-C-HEI group had higher concentrations of HDL-C and the apoA1:apoB ratio, lower concentrations of atherogenic particles (apoB), and larger LDL size (estimated by LDL-C:apoB) compared with women in the low-PAEE/low-C-HEI group. Thus, combining a higher diet quality to a higher PAEE seems to have a greater relationship with these lipoprotein parameters than a higher PAEE alone. Larger LDL particles are less atherogenic than smaller, denser ones ${ }^{(42)}$, and HDL-C is inversely and independently related to the risk of CHD and mortality ${ }^{(43,44)}$. Moreover, the ratio apoA1:apoB reflects the balance between anti- and pro-atherogenic particles ${ }^{(45)}$ and is predictive of cardiovascular events ${ }^{(46,47)}$. The present study is the first to show a favourable synergistic association of diet quality and PAEE with blood lipid and lipoprotein profiles in obese subjects. Of note, the lack of difference in TAG, total cholesterol and LDL-C levels between our groups may be secondary to selection bias, as the present study included relatively healthy obese postmenopausal women (total cholesterol $<7.8 \mathrm{mmol} / \mathrm{l}$ and TAG $<4.5 \mathrm{mmol} / \mathrm{l}$ ), whereas there was no cut-off points for HDL-C, apoB or apoA1. Thus, limited variations within the normal range of cholesterol and TAG levels may have limited group differences.

The original HEI has been inversely associated with $\mathrm{CRP}^{(13)}$ after adjustment for potential confounding factors such as physical activities. We previously showed that a high level of PAEE is associated with lower concentrations of hs-CRP and haptoglobin in overweight/obese postmenopausal women ${ }^{(16)}$. In the present analysis, only the women with a combination of high PAEE and C-HEI had lower hs-CRP and not those with high PAEE but low C-HEI. Thus, the effect of PAEE on CRP is dependent on the concomitant presence of a high diet quality, which was not evaluated in our previous study ${ }^{(16)}$. On the other hand, haptoglobin levels do not seem to be affected by diet quality as 
(a)

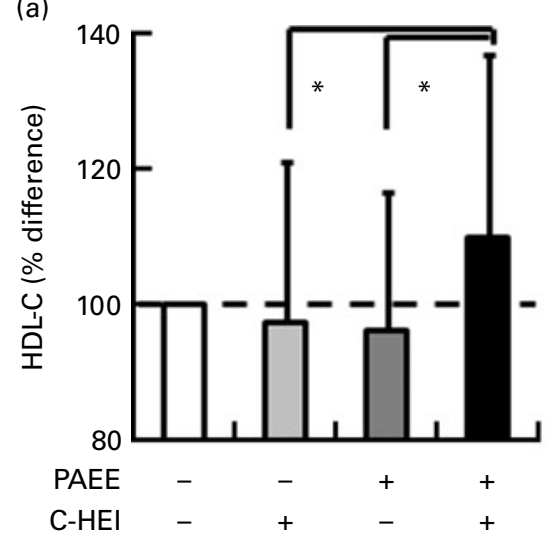

(c)

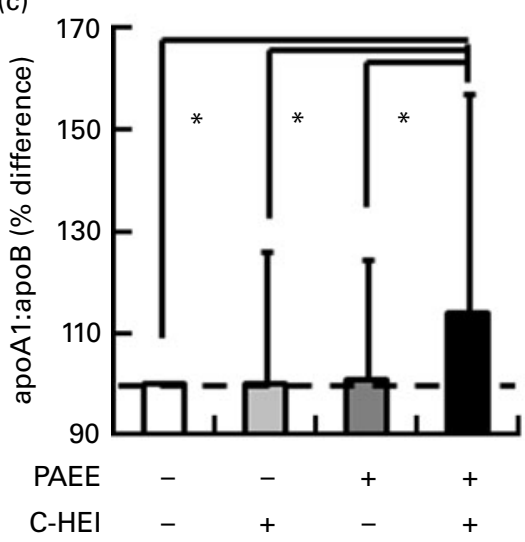

(b)

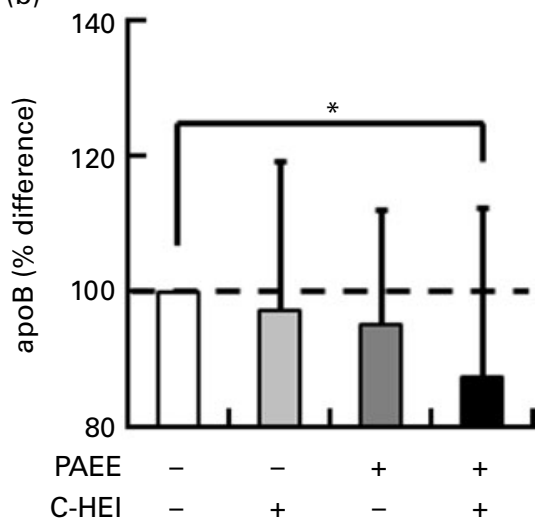

(d)

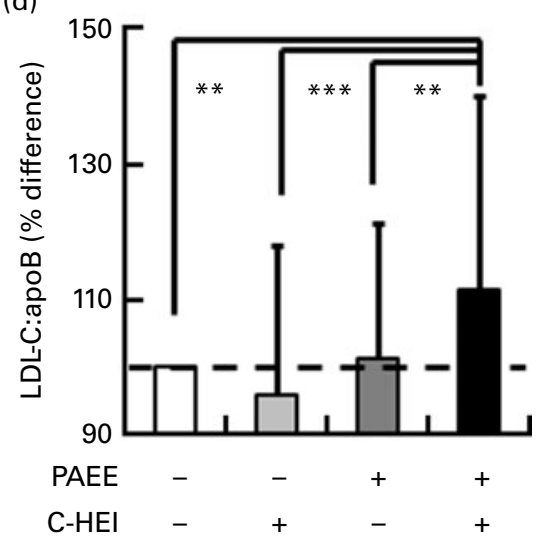

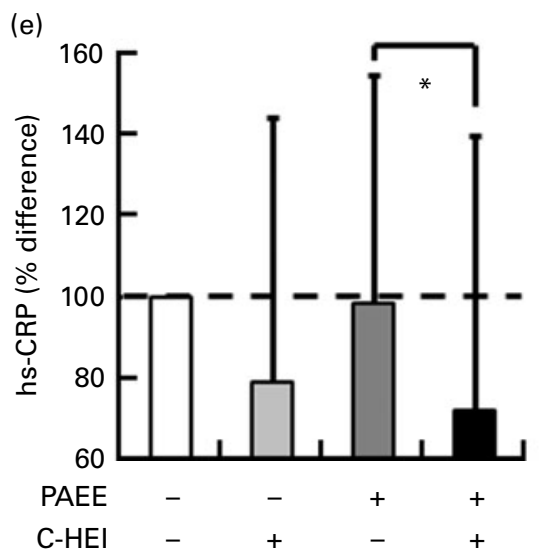

Fig. 2. Percentage of the difference among the four groups for (a)-(d) the blood lipoprotein profile and (e) the inflammatory marker high-sensitivity C-reactive protein (hs-CRP). The low-physical activity energy expenditure (PAEE)/low-Canadian Healthy Eating Index (C-HEI) group was used as the reference group for the percentage calculations. HDL-cholesterol (HDL-C), apoB, apoA1 and LDL-cholesterol (LDL-C) were measured in mmol/l and hs-CRP in mg/l. The symbols ' - , means 'low' and ' + ' means 'high'. Values were significantly different: ${ }^{*} P<0.05,{ }^{* *} P<0.01,{ }^{\star * *} P<0.001$.

PAEE remains its sole correlate in the present study. Of note, PAEE levels measured in a previous study included both structured exercise and non-exercise activities ${ }^{(48)}$. However, as the women included in the present study were inactive with less than $2-3 \mathrm{~h}$ of structured exercises per week, PAEE levels presented here represent mainly non-exercise activities (i.e. occupational and spontaneous physical activities).

While original HEI has been inversely associated with obesity in the Third National Health and Nutrition Examination Survey (NHANES III) ${ }^{(49,50)}$, we found no differences in body composition or the degree of adiposity between the groups using the C-HEI. However, the NHANES III included large populations of both sexes ranging from normal body weight to obesity, while only overweight and obese postmenopausal women were included in the present analysis. Moreover, the present study included women without obesity-associated chronic disease and with high diet quality in comparison with those included in the NHANES III ${ }^{(49,50)}$. About two-thirds of the women had a 'good' diet quality score (mean score 83.5 ) compared with those (mean score 63) in the NHANES III. 
Other studies have reported a lower mean HEI score (varying between 61 and 77) than the one observed in our cohort; the higher score has been reported in women from the Nurses' Health Study ${ }^{(10,13,22,40)}$. It should be noted, however, that women included in the present analysis were recruited to participate in a weight-loss study. Thus, a selection bias of more motivated and health-conscious cohort may have increased the diet quality of the present study.

Despite the beneficial effect of physical activity on BP and insulin sensitivity ${ }^{(51)}$, we found no association between PAEE, C-HEI or their interaction with these parameters in our cohort. While no study has reported any association with insulin resistance, one study has reported a negative association between diet quality, as assessed by the HEI, and BP in men but not in women ${ }^{(52)}$. This absence of association could be secondary to a selection bias, as the present study excluded women with high BP (systolic BP $\leq 160 \mathrm{mmHg}$ or diastolic BP $\leq 100 \mathrm{mmHg}$ ) and those with diabetes. This limited the variation in $\mathrm{BP}$ and the insulin resistance index might have reduced group differences in these parameters. Moreover, the relative small sample size in each group ( $n$ 29-33) may have limited the statistical power of the present analysis. Nevertheless, this further supports the needs to investigate the association between PAEE and the C-HEI with CMR factors in populations with a more disturbed profile such as hypertensive or T2D patients.

In conclusion, the present results indicate that both a good quality of food intake and greater physical activity levels are associated with a healthier cardiometabolic profile in inactive, overweight/ obese postmenopausal women than either behaviour considered separately. Since the diet quality is based on the Canadian dietary guidelines, promotion of these guidelines together with the adoption of higher physical activity levels, including non-exerciserelated daily activity, should be underlined in the management of obesity and its associated CMR factors. CMR benefits associated with the improvement of diet quality and physical activity should be tested in clinical trials. Greater benefits are expected in subjects with the poorest lifestyle behaviours.

\section{Acknowledgements}

We acknowledge the help of A. Tardif for technical assistance in the measurement of inflammatory markers and Dr J.-P. Bastard and Dr S. Fellahi for their participation on inflammatory marker analysis. We also thank L. Messier (registered dietitian) and J. Levasseur (registered nurse) for the coordination of the two studies (MONET and CAO, respectively), and Dr B. Shatenstein for helpful advice. This study was supported by the Canadian Institutes of Health Research (CIHR) New Emerging Team in Obesity (University of Montreal and University of Ottawa, MONET project) and from Genome Canada-Quebec (CAO project) (to R. R.-L.), Fonds de la Recherche en Santé du Québec (FRSQ) (doctoral scholarship to M.-E. L.), CIHR New Investigator Award (M. F.), CIHR/Merck-Frosst New Investigator Award (E. D.), Canadian Foundation for Innovation New Opportunities Award and an Early Research Award (Ontario) (E. D.), FRSQ and chair for clinical research J.-A. de Sève at the IRCM (Montreal Institute for Clinical Research) (R. R.-L.), gift of antibodies from Beckman Coulter. The authors declare that there are no conflicts of interest. The authors' responsibilities were as follow: M.-E. L. and I. S. contributed to the analyses of the food records by the Food Processor SQL program; M.-E. L. contributed to the data collection, calculated the C-HEI score and performed the statistical analyses; M.-E. L., M. F. and R. R.-L. interpreted the data; M.-E. L. wrote the first draft of the manuscript. All authors contributed to the writing of the manuscript and approved the final version of the manuscript.

\section{References}

1. Zalesin KC, Franklin BA, Miller WM, et al. (2011) Impact of obesity on cardiovascular disease. Med Clin North Am 95 , 919-937.

2. Cardiometabolic Risk Working Group: Executive CommitteeLeiter LA, Fitchett DH, et al. (2011) Cardiometabolic risk in Canada: a detailed analysis and position paper by the cardiometabolic risk working group. Can J Cardiol 27, e1-e33.

3. Du H \& Feskens E (2010) Dietary determinants of obesity. Acta Cardiol 65, 377-386.

4. Lichtenstein AH, Appel LJ, Brands M, et al. (2006) Summary of American Heart Association Diet and Lifestyle Recommendations revision 2006. Arterioscler Thromb Vasc Biol 26, 2186-2191.

5. Pai JK, Hankinson SE, Thadhani R, et al. (2006) Moderate alcohol consumption and lower levels of inflammatory markers in US men and women. Atherosclerosis 186, 113-120.

6. Liese AD, Weis KE, Schulz M, et al. (2009) Food intake patterns associated with incident type 2 diabetes: the Insulin Resistance Atherosclerosis Study. Diabetes Care 32, 263-268.

7. Mozaffarian D, Pischon T, Hankinson SE, et al. (2004) Dietary intake of trans fatty acids and systemic inflammation in women. Am J Clin Nutr 79, 606-612.

8. Malik VS, Popkin BM, Bray GA, et al. (2010) Sugarsweetened beverages and risk of metabolic syndrome and type 2 diabetes: a meta-analysis. Diabetes Care 33, 2477-2483.

9. Mozaffarian D, Kumanyika SK, Lemaitre RN, et al. (2003) Cereal, fruit, and vegetable fiber intake and the risk of cardiovascular disease in elderly individuals. JAMA $\mathbf{2 8 9}$, 1659-1666.

10. Fung TT, McCullough ML, Newby PK, et al. (2005) Dietquality scores and plasma concentrations of markers of inflammation and endothelial dysfunction. Am J Clin Nutr 82, 163-173.

11. Wolongevicz DM, Zhu L, Pencina MJ, et al. (2010) Diet quality and obesity in women: the Framingham Nutrition Studies. Br J Nutr 103, 1223-1229.

12. Kennedy ET, Ohls J, Carlson S, et al. (1995) The Healthy Eating Index: design and applications. J Am Diet Assoc 95, 1103-1108.

13. Ford ES, Mokdad AH \& Liu S (2005) Healthy Eating Index and C-reactive protein concentration: findings from the National Health and Nutrition Examination Survey III, 1988-1994. Eur J Clin Nutr 59, 278-283.

14. Kant AK \& Graubard BI (2005) A comparison of three dietary pattern indexes for predicting biomarkers of diet and disease. J Am Coll Nutr 24, 294-303.

15. Kraus WE, Houmard JA, Duscha BD, et al. (2002) Effects of the amount and intensity of exercise on plasma lipoproteins. $N$ Engl J Med 347, 1483-1492.

16. Lavoie ME, Rabasa-Lhoret R, Doucet E, et al. (2010) Association between physical activity energy expenditure and inflammatory markers in sedentary overweight and obese women. Int J Obes (Lond) 34, 1387-1395. 
17. Karelis AD, Lavoie ME, Messier V, et al. (2008) Relationship between the metabolic syndrome and physical activity energy expenditure: a MONET study. Appl Physiol Nutr Metab 33, 309-314.

18. Hamman RF, Wing RR, Edelstein SL, et al. (2006) Effect of weight loss with lifestyle intervention on risk of diabetes. Diabetes Care 29, 2102-2107.

19. Manini TM, Everhart JE, Patel KV, et al. (2006) Daily activity energy expenditure and mortality among older adults. JAMA 296, 171-179.

20. Joosten MM, Grobbee DE, van der ADL, et al. (2010) Combined effect of alcohol consumption and lifestyle behaviors on risk of type 2 diabetes. Am J Clin Nutr 91, 1777-1783.

21. Brochu M, Malita MF, Messier V, et al. (2009) Resistance training does not contribute to improving the metabolic profile after a 6-month weight loss program in overweight and obese postmenopausal women. J Clin Endocrinol Metab 94, 3226-3233.

22. Shatenstein B, Nadon S, Godin C, et al. (2005) Diet quality of Montreal-area adults needs improvement: estimates from a self-administered food frequency questionnaire furnishing a dietary indicator score. J Am Diet Assoc 105, 1251-1260.

23. St-Onge M, Mignault D, Allison DB, et al. (2007) Evaluation of a portable device to measure daily energy expenditure in free-living adults. Am J Clin Nutr 85, 742-749.

24. Black AE, Coward WA, Cole TJ, et al. (1996) Human energy expenditure in affluent societies: an analysis of 574 doublylabelled water measurements. Eur J Clin Nutr 50, 72-92.

25. Reed GW \& Hill JO (1996) Measuring the thermic effect of food. Am J Clin Nutr 63, 164-169.

26. Schectman G, Patsches M \& Sasse EA (1996) Variability in cholesterol measurements: comparison of calculated and direct LDL cholesterol determinations. Clin Chem $\mathbf{4 2}$, $732-737$.

27. Sniderman A, Vu H \& Cianflone K (1991) Effect of moderate hypertriglyceridemia on the relation of plasma total and LDL apo B levels. Atherosclerosis 89, 109-116.

28. Matthews DR, Hosker JP, Rudenski AS, et al. (1985) Homeostasis model assessment: insulin resistance and beta-cell function from fasting plasma glucose and insulin concentrations in man. Diabetologia 28, 412-419.

29. Karelis AD, Faraj M, Bastard JP, et al. (2005) The metabolically healthy but obese individual presents a favorable inflammation profile. $J$ Clin Endocrinol Metab 90, 4145-4150.

30. Jialal I, Devaraj S \& Venugopal SK (2004) C-reactive protein: risk marker or mediator in atherothrombosis? Hypertension 44, 6-11.

31. Faraj M, Messier L, Bastard JP, et al. (2006) Apolipoprotein B: a predictor of inflammatory status in postmenopausal overweight and obese women. Diabetologia 49, 1637-1646.

32. Strychar I, Lavoie ME, Messier L, et al. (2009) Anthropometric, metabolic, psychosocial, and dietary characteristics of overweight/obese postmenopausal women with a history of weight cycling: a MONET (Montreal Ottawa New Emerging Team) study. J Am Diet Assoc 109, 718-724.

33. Black AE \& Cole TJ (2000) Within- and between-subject variation in energy expenditure measured by the doublylabelled water technique: implications for validating reported dietary energy intake. Eur J Clin Nutr 54, 386-394.

34. Karelis AD, Lavoie ME, Fontaine J, et al. (2010) Anthropometric, metabolic, dietary and psychosocial profiles of underreporters of energy intake: a doubly labeled water study among overweight/obese postmenopausal women a Montreal Ottawa New Emerging Team study. Eur J Clin Nutr 64, 68-74.
35. Goodpaster BH, Delany JP, Otto AD, et al. (2010) Effects of diet and physical activity interventions on weight loss and cardiometabolic risk factors in severely obese adults: a randomized trial. JAMA 304, 1795-1802.

36. Knowler WC, Barrett-Connor E, Fowler SE, et al. (2002) Reduction in the incidence of type 2 diabetes with lifestyle intervention or metformin. $N$ Engl J Med 346, 393-403.

37. Tuomilehto J, Lindstrom J, Eriksson JG, et al. (2001) Prevention of type 2 diabetes mellitus by changes in lifestyle among subjects with impaired glucose tolerance. $N$ Engl J Med $\mathbf{3 4 4}$, 1343-1350.

38. Belalcazar LM, Reboussin DM, Haffner SM, et al. (2010) A 1year lifestyle intervention for weight loss in individuals with type 2 diabetes reduces high C-reactive protein levels and identifies metabolic predictors of change: from the Look AHEAD (Action for Health in Diabetes) study. Diabetes Care 33, 2297-2303.

39. Laaksonen DE, Lindstrom J, Lakka TA, et al. (2005) Physical activity in the prevention of type 2 diabetes: the Finnish diabetes prevention study. Diabetes 54, 158-165.

40. Weinstein SJ, Vogt TM \& Gerrior SA (2004) Healthy Eating Index scores are associated with blood nutrient concentrations in the third National Health And Nutrition Examination Survey. J Am Diet Assoc 104, 576-584.

41. Hann CS, Rock CL, King I, et al. (2001) Validation of the Healthy Eating Index with use of plasma biomarkers in a clinical sample of women. Am J Clin Nutr 74, 479-486.

42. Rizzo M, Berneis K, Corrado E, et al. (2006) The significance of low-density-lipoproteins size in vascular diseases. Int Angiol 25, 4-9.

43. Cooney MT, Dudina A, De Bacquer D, et al. (2009) HDL cholesterol protects against cardiovascular disease in both genders, at all ages and at all levels of risk. Atherosclerosis 206, 611-616.

44. Muntner P, Lee F \& Astor BC (2011) Association of highdensity lipoprotein cholesterol with coronary heart disease risk across categories of low-density lipoprotein cholesterol: the atherosclerosis risk in communities study. Am J Med Sci 341, 173-180.

45. Walldius G \& Jungner I (2004) Apolipoprotein B and apolipoprotein A-I: risk indicators of coronary heart disease and targets for lipid-modifying therapy. J Intern Med 255 , 188-205.

46. Walldius G, Jungner I, Aastveit AH, et al. (2004) The apoB/ apoA-I ratio is better than the cholesterol ratios to estimate the balance between plasma proatherogenic and antiatherogenic lipoproteins and to predict coronary risk. Clin Chem Lab Med 42, 1355-1363.

47. Yusuf S, Hawken S, Ounpuu S, et al. (2004) Effect of potentially modifiable risk factors associated with myocardial infarction in 52 countries (the INTERHEART study): case-control study. Lancet 364, 937-952.

48. Levine JA (2007) Nonexercise activity thermogenesisliberating the life-force. J Intern Med 262, 273-287.

49. Guo X, Warden BA, Paeratakul S, et al. (2004) Healthy Eating Index and obesity. Eur J Clin Nutr 58, 1580-1586.

50. Tande DL, Magel R \& Strand BN (2010) Healthy Eating Index and abdominal obesity. Public Health Nutr 13, 208-214.

51. Bassuk SS \& Manson JE (2005) Epidemiological evidence for the role of physical activity in reducing risk of type 2 diabetes and cardiovascular disease. J Appl Physiol 99, 1193-1204.

52. Drewnowski A, Fiddler EC, Dauchet L, et al. (2009) Diet quality measures and cardiovascular risk factors in France: applying the Healthy Eating Index to the SU.VI.MAX study. J Am Coll Nutr 28, 22-29. 